\title{
A educação para o esporte na família
}

\author{
Education for sport in the family
}

\section{Denilson Geraldo*}

Pontifícia Universidade Católica de São Paulo, (PUC-SP), São Paulo, SP, Brasil

\section{Resumo}

A sociabilidade humana pelo esporte exige uma aproximação da experiência de família onde os pais, como primeira referência educacional, são os formadores da pessoa em todas as dimensões. A prática esportiva tem o objetivo de uma vida saudável, possibilitando o bem estar físico, psíquico, espiritual, moral, social e não somente o desempenho e os resultados. Neste sentido, o esporte paraolímpico é significativo aos atletas e à sociedade, contribuindo para a construção de um mundo verdadeiramente pluralista. 0 grande risco do esporte, com sua múltipla e avassaladora oferta de consumo, é a tristeza individualista que pode ser superada com a educação para o lúdico recebida na família. A presença e participação dos pais na formação da pessoa são fundamentais para o conceito de democratização do esporte e participação social através da atividade de recreação, fazendo com que as pessoas se respeitem

* DG: Doutor em Direito Canônico, e-mail: dgeraldo@pucsp.br 
como imagem e semelhança de Deus. Tudo considerado, esta formação para o esporte inicia-se na família, primeira e fundamental escola de humanização.

Palavras-chave: Esporte. Família. Educação. Saúde. Democracia.

\section{Abstract}

The human sociability by sport requires an approximation of the family experience where parents, as first educational reference, are the trainers of the person in all dimensions. Sports practice aims to achieve a healthy lifestyle, allowing physical, mental, spiritual, moral, social well being and not only the performance and results. In this sense, Paralympics sport is significant to athletes and society, contributing to the construction of a truly pluralistic world. The major risk of the sport, with its multiple and overwhelming supply of consumption is the individualistic sadness, that can be overcome with education for the playful welcomed into the family. The presence and participation of parents in the education of the person are fundamental to the concept of democratization of sport and social participation through recreation activity, causing people to respect as image and likeness of God. All things considered, this training for the sport begins in the family, first and fundamental school of humanization.

Keywords: Sport. Family. Health. Education. Democracy.

\section{Introdução}

A quantidade de envolvidos socialmente no esporte é grande em todo o mundo, seja como praticante seja como espectador ou torcedor. Outros são denominados de produtores esportivos com uma relação direta ou indireta com o esporte, como os treinadores, administradores e jornalistas cuja importância é valorizada por representar uma força de trabalho derivada do esporte. A exposição diária da atividade esportiva pela mídia prova de forma inequívoca o interesse da população mundial 
por este fenômeno, provocando o surgimento ininterrupto de novas modalidades esportivas com diferentes perspectivas, evidenciando que o esporte, pela sua crescente relevância social, tornou-se um dos mais importantes fenômenos sociais.

É utópico considerar o mundo esportivo não patrocinado por empresas, governos e clubes que desempenham uma grande ajuda ao desenvolvimento do esporte. No entanto, não parece fora da realidade afirmar que o esporte enquanto atividade tem seu fundamento na família. Neste ambiente a prática esportiva trabalha com o lúdico, com a alegria da presença do outro, com a descontração, que não exige resultados e o perdedor se celebra tanto quanto o vencedor. O lúdico é também ensinado em casa, pois o lar não é apenas um lugar de descanso, mas fundamentalmente, um centro formador, uma escola dos mais altos valores.

Não é necessário mistificar a família ou fazer dela uma ideologia, para reivindicar a sua verdadeira natureza e conferir-lhe o justo valor subjetivo e ativo no mundo esportivo. Relacionando o tema com a Teologia, o ponto referencial é a formação da pessoa que não se faz sozinha, mas na família por meio da abertura e do diálogo estabelecidos entre os seus membros e também com Deus, Fonte do ser. O livro do Gênesis apresenta o homem e a mulher criados à imagem e semelhança de Deus que, no acolhimento recíproco, se reconhecem feitos um para o outro (cf. Gn 1,24-31; $2,4 b-25)$ e se tornam colaboradores de Deus no acolhimento e transmissão da vida, cooperando de modo único na obra do Criador e na perspectiva da beleza do amor humano, espelho do divino. O tema é desenvolvido sobretudo, no Cântico dos Cânticos e nos Profetas. Esta realidade foi apresentada pelo Cristo (Ef 5, 31-32), tendo o amor de Deus como a medida do amor humano e formando na família uma comunidade de vida e amor (cf. SÍNODO DOS BISPOS, 2013, n.1-6).

Aqui se encontra a reflexão teológica que se dedica a clarificar o conceito de esporte em seu início, isto é, em Deus e na família. De fato, no que se refere ao esporte, Jesus Cristo ilumina a inteligência e a liberdade do homem de hoje, e — sendo Imagem do Deus invisível — revela plenamente o homem ao próprio homem, indicando-lhe o caminho para a realização de sua altíssima vocação para o amor, que se dá na relação com o outro. 


\section{A família internaliza os valores do esporte}

A prática esportiva tem suas raízes na formação da personalidade e na conduta do ser humano. A figura materna e paterna são os primeiros contatos que a criança tem com o mundo. Através desse contato, são construídas as relações com as pessoas que estão a sua volta, bem como o conhecimento de tudo que permeia o mundo e a personalidade da pessoa. As relações que o ser humano estabelece durante a infância são fundamentais para construção e desenvolvimento das relações da fase adulta, servindo de ferramenta para a formação da dimensão social. Neste sentido, o esporte é um instrumento na formação do ser humano e sua prática reflete a personalidade, os valores e a conduta que adquiridas na própria família, origem natural de todo ser humano (cf. MONTEIRO, 2007, p. 67).

Este dever de educar a criança na família mergulha as raízes na vocação primordial dos cônjuges à participação na obra criadora de Deus: gerando no amor e por amor uma nova pessoa, que traz em si a vocação ao crescimento e ao desenvolvimento. Os pais assumem, por isso mesmo, o dever de ajudar eficazmente a viver uma vida plenamente humana. Esta função educativa é de tamanha responsabilidade que, onde não existe, será suprida com muitas dificuldades. Com efeito, é missão dos pais criar um ambiente de tal modo animado pelo amor que favoreça a completa educação dos filhos (cf. JOÃO PAULO II, 1982, n. 36), como primeira escola de virtudes sociais de que a vida em sociedade, especialmente o mundo esportivo, tem necessidade.

A formação para a sociabilidade humana exige a família, mas também o apoio de pessoas, instituições e governos. Ao longo da História, o ser humano se associou a tantos outros indivíduos formando complexas sociedades, grupos, nações, povos, permitindo uma maior adaptação à vida. Contudo, temos na família uma comunidade natural, na qual se experimenta a primeira e fundamental sociabilidade humana, o fundamento e a melhor garantia contra toda tendência individualista ou coletivista de sociedade, porque nela a pessoa está sempre no centro enquanto fim e nunca como meio. Na família, a pessoa é a razão de tudo o que existe. E, a própria instituição familiar não poupa esforços por um de seus membros sequer, porque a pessoa tem o mais alto valor. Não importa a idade, a 
condição física ou mental, a família considera cada um de seus membros como um fim em si mesmo pelo fato de ser pessoa, como um direito nato de pertença, levando a considerar que o bem das pessoas e o bom funcionamento da sociedade estejam estreitamente conexos com a comunidade conjugal (cf. PONTIFÍCIO CONSELHO JUSTIÇA E PAZ, 2005, n. 213).

A experiência que a pessoa traz de sua família é a escola para uma prática esportiva equilibrada e sadia. A formação para os valores provenientes dos pais é a condição de poder caminhar na mesma trilha, possuindo gosto pela imitação, razão pela qual, boa parte da cultura tem sua origem. O Cristo impelia os líderes da comunidade a não se limitar à cópia de algo externo, mas exigia que as atitudes fossem coerentes, trazendo a marca de um autêntico testemunho que arrasta seguidores (cf. LOBATO, 2007, p. 770). De fato, esta participação educativa forma o caráter do futuro esportista e representa uma escola imprescindível para a formação de um atleta coerente e integro com o mundo esportivo.

A mentalidade corrente em alguns ambientes esportistas de "sempre levar vantagem”, impregnada de práticas antiéticas, pode ter sua origem na formação marcada pelo pragmatismo e o relativismo. Às vezes, pais e responsáveis, no intuito de querer dar o melhor aos filhos — materialmente considerado - acabam orientando-os a desrespeitar as regras e os direitos que garantem o bem comum. Não se pode deixar de levar em consideração um princípio: o melhor educador é o exemplo, aprende-se melhor pela experiência. Os caminhos educacionais são semelhantes às trilhas nas florestas: não bastam os sinais indicadores, mas é preciso um guia, que vá à frente e mostre, com a sua experiência, as passagens mais seguras, os lugares menos perigosos, as picadas mais diretas (cf. CNBB, 2004, n. 120 e 136). Da mesma forma, a verdade e a autenticidade da prática esportiva encontra seu fundamento numa educação que teve como modelo os próprios pais, primeiros treinadores dos futuros atletas.

Neste sentido, a educação está necessariamente aberta aos valores fortalecidos pelas virtudes com suas raízes na família. A virtude é um hábito que coloca em condições de fazer algo muito bem, permite alcançar a ciência, gozar a sabedoria ou aplicar uma arte à vida real ao desenvolvimento da personalidade (cf. LOBATO, 2007, p. 771). Na literatura sobre o esporte, desde as primeiras sistematizações das atividades físicas que 
se têm registro, a finalidade do desenvolvimento e da aquisição de valores morais está colocada não só como objetivo primeiro, mas como efeito automático e proveniente de sua própria natureza. De fato, como observa Agricola, a associação da prática de atividades físicas com a moral e a vivência das virtudes permeou praticamente todas as publicações na área da Educação Física no século XIX (cf. AGRICOLA, 2007, p. 37).

Não podemos descartar que a formação na família não orientada aos valores e às virtudes pode influenciar o comportamento ou condutas agressivas por parte de esportistas ou torcedores. Tais atitudes abrangem a manipulação das regras que regem determinado esporte, a não aceitação da autoridade do árbitro e a incapacidade de assimilar a derrota. O esporte que se caracteriza como uma ferramenta de socialização, neste caso, torna-se causador de discórdias e violências (cf. MONTEIRO, 2007, p. 78). Neste aspecto, podemos propor uma engajada teologia da libertação como ferramenta simbólica para fazer valer sua necessidade de libertação das formas mais diversas de opressão com um caráter internacional, inter-religioso, interdisciplinar. Trata-se de uma sensibilidade hermenêutica e de conteúdo conjugadas (cf. MOREIRA, 2014, p. 29-31), para que o esporte seja um autêntico espaço de sociabilidade lúdico.

No esporte, atitudes com critérios morais compreendem o respeito pelas regras socialmente instituídas e acompanhadas do senso de justiça. Essas regras manifestam-se no comportamento individual de dois modos: atitudes internalizadas ou externamente motivadas. Quando as regras sociais são internalizadas, o sujeito age naturalmente como se fosse sua segunda natureza, sem que para isso haja algum tipo de coação. A opção pelo comportamento moral, neste caso, é orientada e acompanhada pelo senso de justiça. Tal comportamento é transmitido geralmente, por alguém de importância significativa para a pessoa, por exemplo, seus próprios familiares. O comportamento moral não internalizado e externamente motivado é adotado por uma pressão coercitiva proveniente do medo de punições. Neste segundo modelo, é o receio de sansões que mantém o padrão de comportamento moral. A possibilidade de não ser descoberto aumenta significativamente a opção pelo comportamento socialmente incorreto ou imoral. Nesta perspectiva, a pessoa conhece as regras sociais, mas as adota se tiver a sensação de que, se não adotar, será 
descoberta e repreendida. Isso nos mostra que o comportamento moral verdadeiro é efetivamente internalizado e assumido com opção pessoal motivada pela figura de alguém que influenciou decisivamente a formação da pessoa. Garantir a disseminação desses padrões mediante a formação constante e permanente e não mediante o medo das punições, é o grande desafio das instituições que trabalham na educação e, principalmente, da família (cf. AGRICOLA, 2007, p. 41-42).

Deste modo e caminhando sempre nesta direção, considera-se que a socialização humana tem início na família e, quando esta educação é alterada ou corrompida na busca desmedida de vantagens em prejuízo ao bem comum, então, a pessoa é atingida em sua natureza social. O que está em jogo na formação dos valores na vida familiar e no mundo esportivo, além de toda pedagogia, é a formação da pessoa humana que implica na vivência do amor e da verdade com sua origem na família e na relação desta com o Criador. A sociedade é o local da verdade, ao menos de iure, e a família é a fundamental expressão da sociedade humana, isto é, em relação à família, cuja origem está na união conjugal, a pessoa faz a experiência de ser verdadeira não por medo de coação, mas por amor como um valor internalizado. A verdade é um bem para a pessoa e a criança é educada e cresce com uma personalidade delineada pelo único fato de pertencer à família. Em tempos caracterizados pela mentira e pela violência, a família se apresenta, mais do que nunca, como o abrigo ou como lugar privilegiado da verdade, ou melhor, da vida na verdade, que é ao mesmo tempo uma vida de verdade. Aqui reside a ousadia e a amorosa exigência educativa da família (cf. VALENCIA, 2007, p. 378-383).

Neste enfoque, uma pergunta não se cala: o causador da violência seja como praticante, seja como espectador do esporte, traz consigo uma agressividade a partir da sua experiência familiar? Podemos dizer que em grande parte sim, pois o esporte carrega elementos de humanização à sociedade e ao indivíduo, na medida em que propõe a possibilidade de coexistência pacífica entre as diferenças e o espírito de solidariedade. Uma sociedade marcada pela violência encontra na família um caminho de humanização ao canalizar essa força para algo maior, internalizando valores sociais como a cooperação, solidariedade e amor (cf. AGRICOLA, 2007, p. 43). 
A experiência de doação total na vida matrimonial é fator decisivo contra o fanatismo esportivo, causa de violência à dignidade do ser humano. Seja como praticante ou torcedor não será possível doar-se por inteiro, mas somente na família e a Deus que a entrega de si se efetiva.

\section{A saúde e a valorização do corpo na prática esportiva}

Há três degenerações que podem ocorrer no campo do esporte e que devem ser evitadas: A primeira delas é quando o esporte visa apenas o lucro e os resultados meramente econômicos e a pessoa não é considerada; a segunda degeneração é quando se alimenta a violência e a terceira quando o corpo dos atletas é reduzido a objeto e são difundidas práticas de uso de drogas para melhorar o desempenho. Individualizado no fenômeno obsessivo por se tornar sadio, percebido como uma espécie de objeto de resultados e veneração, utilizando-se todos os recursos e instrumentos disponíveis com a mentalidade de que quanto mais forte e mais músculos melhor, dissocia do esporte a moralidade e compromete decisivamente a saúde (cf. AGNELO, 2007, p. 163-164).

Saúde é, conforme definição da Organização Mundial da Saúde (OMS), "o estado de pleno bem-estar físico, psíquico e social e não somente a ausência de doenças e enfermidades" (PRIVITERA, 2004, p. 1052-1054). O conceito oferecido pela OMS remete ao conceito de pessoa na sua totalidade, no seu destino em conexão com a realização como um todo. Se o conceito de saúde se limitasse ao aspecto fisiológico, a saúde seria apenas ausência de dor e exuberância de vitalidade corporal. A definição da OMS estabelece a relação entre a saúde e o geral bem-estar humano (cf. MARRA, 1997, p. 917).

Por isso, tal conceito de saúde implica na experiência de equilíbrio psicofísico e na busca cotidiana de bem-estar, e a cura não se identifica com a simples retirada dos sintomas, mas no reencontro de um novo equilíbrio por meio de um processo de crescimento da consciência e da responsabilidade. A saúde da pessoa é um estilo de vida, é um paradigma que se define na relação com o trabalho, a habitação, a alimentação, higiene e que reflete no esporte. A promoção da saúde tem sua origem 
em comportamentos favoráveis ao bem-estar integral do ser humano e, consequentemente, evitando o surgimento de patologias. A clarificação do conceito de saúde coloca como premissa a condição ética para a prática do esporte (cf. SPINSANTI, 2004, p. 1049-1052). Nesta perspectiva, se reconhece a significativa contribuição do esporte paraolímpico para a construção de um mundo verdadeiramente pluralista, democrático, que sabe respeitar e conviver com as diferenças, pois o "respeito à vida corporal, insurgindo-se contra uma concepção neopagã que tende a promover o culto do corpo e a idolatrar a perfeição física pode conduzir à perversão das relações humanas" (JOÃO PAULO II, 1993, n. 2289).

Sendo assim, a questão da corporeidade está na percepção do seu autêntico significado e na aceitação da pessoa expressa. O caminho indicado pela tradição cristã, herdeira do patrimônio bíblico, não reduz a pessoa à sua materialidade, nem à sua espiritualização, mas a unidade. Esta reflexão pode ampliar-se, considerando a reciprocidade entre o homem e a mulher na vida conjugal e se inscreverá na raiz de todas as experiências de coletividade humana, especificando um modo próprio e pessoal de viver a comunhão, demonstrando como o ser humano se estrutura como dom para se oferecer ao outro (cf. AGNELO, 2007, p. 165-167), sendo que - na família, primeira escola de cuidado com a saúde - a prática esportiva assinala o valor da pessoa em sua estrutura física, moral, espiritual, mental e social.

\section{0 lúdico na família e no esporte}

O Instrumento de Trabalho (instrumentum laboris) para o Sínodo dos Bispos sobre os desafios pastorais da família no contexto da evangelização, considerou algumas situações particulares como as expectativas de rendimento escolar e o valor excessivo atribuído aos títulos de estudo com impacto negativo sobre a família, bem como a frequência nos cursos que destinam-se à consecução de particulares metas formativas depois dos horários escolares, acarretando a falta de tempo livre para dedicar ao jogo das crianças (cf. SÍNODO DOS BISPOS, 2014, n. 76). O grande risco do mundo atual, com sua múltipla e avassaladora oferta de consumo, "é 
a tristeza individualista que não deixa espaço para a família, não se ouve a voz de Deus, já não se goza da doce alegria do seu amor, nem fervilha o entusiasmo de fazer o bem. Este não é o desígnio de Deus para o ser humano, não é a vida no Espírito que jorra do coração de Cristo ressuscitado" (FRANCISCO, 2013, n. 2).

Para o cristianismo, a vida interior e a união com Cristo estão repletas de alegria: "De novo vos verei, e o vosso coração se alegrará, e ninguém será capaz de vos tirar a vossa alegria" (Jo 16,22). "Tu pões no meu coração, Senhor, uma alegria maior do que aquela que transborda depois de uma copiosa colheita" (Sl 4,8). A alegria e a paz vividas na família servem de modelo para outras virtudes humanas e cristãs como a honestidade, solidariedade, justiça e tantas outras (cf. CNBB, 2004, n. 138 e 140).

Uma imagem alegre do esporte é expressada por meio das práticas populares originadas nos grupos ou comunidades onde os protagonistas, voluntariamente, tornam-se os idealizadores, os agentes organizadores e os participantes das práticas criadas. Por tudo isto é que o esporte, como participação ou esporte popular, é reconhecido como aquela dimensão social mais inter-relacionado com os caminhos democráticos que equilibra o quadro de desigualdades de oportunidades como o lúdico na família onde todos podem participar. O esporte popular tem estreita relação com o lazer e o tempo livre, cuja manifestação em espaços não comprometidos com o resultado e fora das obrigações da vida diária, vem com o propósito de descontração, diversão, desenvolvimento pessoal e de estabelecer relações entre pessoas de livre participação e não por obrigação (cf. TUBINO, 1992, p. 34-35).

O esporte tem como função o lúdico e a transmissão de valores, porém, afirmar que ele cumpre esse papel é uma posição bastante otimista e talvez, ingênua, pois não podemos deixar de considerar que o esporte atual está profundamente determinado pela economia e pelo desempenho. O uso ideológico do fenômeno esportivo, no sentido de desviar a atenção, em especial da parcela social mais pobre, de uma situação social caótica, aliando-se ao espetáculo do fenômeno, supervaloriza os padrões estéticos do alto rendimento. O lúdico, nesta perspectiva desaparece e o esporte, o corpo, o desempenho é transformado em mera mercadoria que distorce a condição humana, canalizando tudo para o desejo e a 
necessidade, fazendo com que a afirmação acerca do valor do esporte para humanização seja mero discurso retórico (cf. AGRICOLA, 2007, p. 48-49).

\section{Conclusão}

A prática esportiva é essencialmente vinculada ao prazer. Não pode, contudo, ser entendida como simples busca de resultado sem critérios morais, mas é um instrumento de promoção e de participação social que tem seu fundamento em Deus e na vida familiar. Deste modo, o esporte se apresenta aos praticantes e espectadores a oportunidade de formação moral, de prazer, alegria, oferecendo ao ser humano a oportunidade de socialização Concebido desse modo, o esporte traz em sua origem a vida familiar que implica no reconhecimento do outro como dom de amor que, além da doação daquilo que se tem, realiza-se na doação de si e implica a reciprocidade.

Não tendo a experiência familiar como referência, o amor pelo esporte arrisca transformar-se em fanatismo, em amor cego, fechado, incapaz de compreender e respeitar os outros, levando à mentira, falsidade e, em casos extremos, à violência - que são valores opostos ao que é o ser humano. Em suma, o esporte praticado de forma saudável leva a amar o próximo e a Deus que é Amor. Concebido deste modo, o ser humano que pratica o esporte é pessoa, não apenas indivíduo que se concentra na singularidade e se coloca em oposição à sua essência, termo que recolhe o dado estrutural da relação como constitutivo de sua própria natureza. Criado à imagem de Deus, o ser humano reflete atributos essenciais das Pessoas Divinas, como a instauração de relações, participação e solidariedade. Assim sendo, o homem é imagem de Deus não tanto no momento da solidão, mas na comunhão; e se a solidão é pressuposto de sua existência pessoal, também ela se constitui princípio de relação (cf. AGNELO, 2007, p. 166-167). A partir desta fundamentação antropológica, torna-se uma exigência democratizar o esporte e assegurar a igualdade de acesso à prática esportiva para todos. Desse modo, percebe-se que a utilização do esporte como meio de democratização, será sempre uma consequência da amplitude da prática esportiva. Por estas afirmações é possível explicar 
que as ações na área social do esporte, para que estejam contempladas com preceitos democráticos, terão que passar pelo esporte enquanto participação (TUBINO, 1992, p. 22).

Enfim, gratuidade e liberdade são características do esporte que, no sentido mais amplo e criativo do termo, pertence à essência da humanidade. O esporte pode ser uma analogia para falar sobre a fé porque representa comunhão, participação, respeito pela dignidade, educação aos valores iniciados na família. É nesse sentido que o papel do esporte transcende a um simples modo de entretenimento e diversão, visto que sua origem última (enquanto dado humano) está em Deus, Fonte do amor e da comunhão. Consequentemente, o esporte pode ser reconhecido como um retorno ao paraíso, pois a saída da seriedade do cotidiano que escraviza é em si um desejo do Altíssimo.

\section{Referências}

AGNELO, G. M. O corpo e os desafios atuais: ética e teologia. In: PONTIFÍCIO CONSELHO PARA A FAMÍLIA. Lexicon: termos ambíguos e discutidos sobre família, vida e questões éticas. Brasília: Edições CNBB, 2007, p. 7161-7169.

AGRICOLA, N. P. A. Esporte, esporte escolar e competição: sentidos, ações e contradições. Goiânia: UCG, 2007.

CONFERÊNCIA NACIONAL DOS BISPOS DO BRASIL [CNBB]. Diretório da Pastoral Familiar. São Paulo: Paulinas, 2004.

FRANCISCO. Exortação Apostólica Evangelii Gaudium. São Paulo: Paulinas, 2013.

JOÃO PAULO II. Catecismo da Igreja Católica. São Paulo: Paulinas, 1993.

JOÃO PAULO II. Exortação Apostólica Familiaris Consortio. São Paulo: Paulinas, 1982. 
LOBATO, A. Personalização. In: PONTIFíciO CONSELHO PARA A FAMÍLIA. Lexicon: termos ambíguos e discutidos sobre família, vida e questões éticas. Brasília: Edições CNBB, 2007, p. 770-771.

MARRA, B. Salute. In: PACOMIO, L.; MANCUSO, V. (Orgs.) Lexicon: Dizionario Teologico Enciclopedico. Roma: Edizione Piemme, 1997, p. 917.

MONTEIRO, A. O. Desporto: da excelência à virtude, um caminho para crianças, Jovens e Adultos. 2007. Braga: Edição Universidade do Minho. (Tese de Doutorado). Universidade do Minho, Braga, Portugal, 2007.

MOREIRA, A. S. Religião Politizada contra violência institucionalizada: a Teologia da Libertação no imaginário religioso mundial. Revista Horizonte, Belo Horizonte, v. 12, n. 33, jan./mar. 2014.

PACOMIO, L.; MANCUSO, V. (Orgs.). Lexicon: Dizionario Teologico Enciclopedico. Roma: Edizione Piemme, 1997.

PONTIFÍCIO CONSELHO JUSTIÇA E PAZ. Compêndio da doutrina social da Igreja. São Paulo: Paulinas, 2005.

PRIVITERA, S., Salute spirituale. In: LEONE, S.; PRIVITERA, S. Nuovo dizionario di bioetica. Milano: Città Nuova, 2004, p. 1052-1054.

RAMSAY, H. Família e filosofia. In: PONTIFÍCIO CONSELHO PARA A FAMÍLIA. Lexicon: termos ambíguos e discutidos sobre família, vida e questões éticas. Brasília: Edições CNBB, 2007, p. 365-374.

SÍNODO DOS BISPOS. III Assembleia geral extraordinária do Sínodo dos Bispos: os desafios pastorais da família no contexto da evangelização (instrumentum laboris). São Paulo: Paulinas, 2014.

SPINSANTI, S. Salute. In: LEONE, S.; PRIVITERA, S. Nuovo dizionario di bioetica. Milano: Città Nuova, 2004, p. 1052. 
TEIXEIRA, M. S.; MOORE, F. E. A mulher e o esporte: a experiência dos municípios do Rio de Janeiro e de São Paulo: relatório final julho 2007. Rio de Janeiro: Edição Instituto Noos, 2008.

TUBINO, M. J. G. Dimensões sociais do esporte. São Paulo: Cortez, 1992.

VALENCIA, F. M. Família e personalismo. In: PONTIFÍCIO CONSELHO PARA A FAMÍLIA. Lexicon: termos ambíguos e discutidos sobre família, vida e questões éticas. Brasília: Edições CNBB, 2007, p. 375-392.

Recebido: 04/08/2014

Received: 08/04/2014

Aprovado: 24/11/2014

Approved: 11/24/2014 